\title{
Effect of Heat Treatments on Wear Behavior of En 45 Spring Steels
}

\author{
T.B. Bastewad ${ }^{1 *}$, S.H. Thakare ${ }^{1}$, P.R. Sapkale ${ }^{2}$, A.K. Kamble ${ }^{1}$ and D.S. Karale ${ }^{1}$ \\ ${ }^{1}$ Department of Farm Power and Machinery, College of Agricultural Engineering and \\ Technology, Dr. P. D. K. V., Akola, (MH) India \\ ${ }^{2}$ Department of Farm Machinery and Power Engineering, Dr.Ulhas Patil College of \\ Agricultural Engineering and Technology, Jalgaon (MH) India \\ *Corresponding author
}

\section{A B S T R A C T}

\section{Keywords}

EN 45, Heat treatment, Steel, wear and $\mathrm{CrN}$ Coating

Article Info

Accepted: 07 February 2019 Available Online: 10 March 2019
Heat treatment is a combination of heating and cooling operations to a metal or alloy in the solid state in a way that will produce desired properties. Due to improper material and surface hardening treatments, the quality of tools does not conform to the Bureau of Indian Standards resulting in high wear rates and reduced life. The experiments were conducted on pin-on disc wear machine with three heat treatments, hardening and tempering, chromium nitride coating and Cryogenic treatment were selected. Minimum wear loss of $0.0064 \mathrm{~g}$ was observed in $\mathrm{T}_{2}$ followed by $0.0071 \mathrm{~T}_{3}, 0.0113 \mathrm{~T}_{1}$ and $0.0684 \mathrm{~g} \mathrm{~T}_{4}$ treatments. The wear loss of materials with harden and tempered, coated and cryogenic treatments were found $35.49,66.42$ and 53.52 per cent less than that of the untreated material.

\section{Introduction}

Critical components of agricultural machinery and implements are those coming into direct contact with the soilor crop. They are exposed to abrasive wear and sometimes impact, therefore requiring a certain level of hardness to be wear resistant. The required mechanical properties are achieved through the process of surface hardening. To achieve the mechanical properties, one has to know the composition of steel and the level of hardness. Heat treatment of steel serves to modify hardness, strength and toughness of the work piece by transforming its structure. The basic procedure of heat treatment involves simply heating and cooling at a faster rate enough to develop the desired properties. The way in which the desired properties are incorporated depends on the temperature to which the steel is to be heated, time that the steel is to be held at this particular temperature and the rate at which the steel is to be cooled from this temperature.

Heat treatment is a combination of heating and cooling operations to a metal or alloy in the solid state in a way that will produce desired properties. Heat treatment can be used to 
change the microstructure and hence the properties of carbon steels. All basic heat treatment processes for steel involve the transformation or decomposition of austenite. The nature and appearance of these transformation products determine the physical and mechanical properties of any given steel.

Now a day nano technology is being used in many fields due to its typical property of anti wear and corrosion. A thin film is a layer of material ranging from fractions of a nanometer to several micrometers in thickness. Deposition of thin films by physical vapour deposition (PVD) techniques, such as sputtering, evaporation and reactive deposition has found wide spread use in many industrial sectors and there is an increasing demand for such coatings with enhanced properties. Sputtering is a process in which atoms are ejected from a solid target material due to bombardment of energetic particles and are deposited on substrate atom by atom. Chromium nitrate $(\mathrm{CrN})$ coatings are principally applied where wear and corrosion protection are major concern. It generally increases the life of the substrate. Singh et al., (2013) studied the effect of cryogenic treatment on the abrasive wear behavior of En 45 spring steel. Cho et al., (2013) investigated that the surface hardening mechanism of $\mathrm{H} 13$ steel after shot peening and ion nitriding. Gupta et al., (2004) claimed that heat treatment is a simple, flexible and cost effective technique. Keeping this view, the present study was conducted to study the effect of heat treatment processes on wear behavior of En 45 spring steel under varying loads and speeds in laboratory.

\section{Materials and Methods}

Experimental procedure adopted for estimating the quantity of wear loss and wear pattern of En 45 spring steel.

\section{Sample preparation}

The number of samples for experimentation purpose was decided as per the plan. The samples having diameter $6 \mathrm{~mm}$ and height of $15 \mathrm{~mm}$ used for wear testing, optical images. The diameter to height ratio for hardness testing samples was kept as $1(6 / 6=1)$.

\section{Heat Treatments}

The purpose of heat treatments is to make a steel more useful by changing or restoring its mechanical properties. For the study three types of heat treatment was selected viz. hardening and tempering, $\mathrm{CrN}$ coating and cryogenic treatment.

\section{Hardening and tempering}

Hardening of EN45steel was done in tubular furnace with controlled heating in steps. Heating was done in steps of $550^{\circ} \mathrm{C}$ for $5 \mathrm{~min}$ and final holding at $910^{\circ} \mathrm{C}$ for $5 \mathrm{~min}$ followed by oil quenching at room temperature for 5 min then air cooled. This was followed by the single tempering at $200^{\circ} \mathrm{C}$ for $2 \mathrm{~h}$ followed by air cooling to room temperature such treatment known as conventional treatment.

\section{Soft tempering}

Post treatment of soft tempering was given to cryotreated specimens in Muffle Furnace (make Process Controls, model - PCF-01, Rating - $3.8 \mathrm{~kW}$, Maximum temperature $600^{\circ} \mathrm{C}$ ) at $100^{\circ} \mathrm{C}$ for 1 hour to cryotreated samples. Thus effects of these post treatments were studied and compared with as-received sample.

\section{Cryogenic treatment}

The cryogenic treatment was given to all conventionally treated specimens as shown in Figure 1 in a computer controlled 
Cryoprocessor (Make Sandmar, Mumbai, cryogenic treatment at $-185^{\circ} \mathrm{C}$ ). These specimens were placed in Cryoprocessor at room temperature and subsequently the temperature of the processor was brought down to $-185^{\circ} \mathrm{C}$ at a cooling rate of $3^{\circ} \mathrm{C} / \mathrm{min}$ by supplying calculated gasified liquid nitrogen through solenoid valve. The cryosoaking period was taken as $16 \mathrm{~h}$. All specimens were removed from the Cryoprocessor and then immediately transferred in a highly insulated thermocole box until it attains room temperature. The entire cryotreated specimens were soft tempered at $100^{\circ} \mathrm{C}$ to relieve cold stresses. The processing parameters used in during cryogenic treatment are given in Table 1.

\section{CrN coating by PVD process}

Test sample pins were used for deposition of the $\mathrm{CrN}$ coatings. The sample surface was polished and then ultrasonically cleaned in alkaline solution. After cleaning Pin samples were dried using hot blow air and then kept in oven for $30 \mathrm{~min}$ at $90^{\circ} \mathrm{C}$. Cleaned pin samples were loaded inside the vacuum chamber.

An industrial cathodic arc evaporation system, SMT 800 Advanced arc system equipped with four cathodes and a rotating carousel holding test sample was used for deposition of the $\mathrm{CrN}$ coatings. Chamber pressure before start of deposition process was in the range of $8.0 \mathrm{x}$ $10^{-3} \mathrm{~Pa}$. After achieving the base vacuum, samples were cleaned using plasma etching process (carried out for $5 \mathrm{~min}$ at $-500 \mathrm{~V}$ ). After plasma etching, deposition of Chromium nitride coating was carried out using $99.99 \%$ pure Chromium cathodes operating at 60A. Coating deposition was carried out using Ultra-high pure (UHP) nitrogen gas at chamber pressure of 1.0 Pa. The substrate bias voltage was kept at $-100 \mathrm{~V}$ and the substrate temperature was approximately $150^{\circ} \mathrm{C}$. The coating process was carried out for 70 minutes. Samples were allowed to cool in the vacuum chamber for 10 minutes and then were unloaded from the chamber.

\section{SEM Microstructures}

A usual metallographic polishing technique was followed. A freshly prepared etchant $4 \%$ Nital was used and observed in Optical Microscope was used for microstructural features.

\section{Hardness testing}

Rockwell hardness testing machine was used for measurement of hardness on $\mathrm{C}$ scale. A minor load of $10 \mathrm{~kg}$ was first applied to seat the indenter. Then major load of $150 \mathrm{~kg}$ was applied for 15 seconds and resistance to indentation was recorded on the dial gauge. An average of three readings was noted as a measure of hardness.

\section{Wear testing}

Pin-on-disc test machine was used for dry sliding wear in which stationary pin was slid against counter face disc. Pin of $6 \mathrm{~mm}$ diameter and $15 \mathrm{~mm}$ height was slid on the circular rotating disc of SAE52100 having diameter $170 \mathrm{~mm}$ and that the hardness was 63 HRC. The parameters used for the wear test are given in Table 2 . The surface roughness of the counter face was maintained constant by polishing with 220 grit paper for $10 \mathrm{~min}$. Before each test, both pin and disc were cleaned with acetone to remove any possible traces of grease and other surface contaminants. The loss in weight measured using analytical digital weighing balance with measuring accuracy of $0.0001 \mathrm{~g}$. The wear rate was calculated by using formula as given in Eq. 1. 


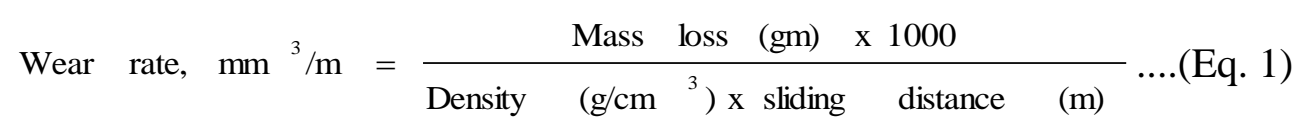

\section{Results and Discussion}

The experiments were conducted in the speed range of $0.5,1.0,1.5$ and $2.0 \mathrm{~m} / \mathrm{s}$, load range of $40,60,80$ and $100 \mathrm{~N}$ and time range 12 to $50 \mathrm{~min}$.

\section{Microstructure analysis}

There are four different types of treatment conditions ( $\mathrm{T} 1$ to $\mathrm{T} 4$ ). It is observed that overall wear resistance is exhibited in decreasing order of their treatment conditions viz. Chromium nitride, Cryogenic treatment, Hardened and tempered and then by control sample. It is noted that highest wear resistance of coating is due to inherent wear resistance of chromium nitride, which has highest hardness of 3100 VHN (to confirm exact hardness reported by SMT). This increased wear resistance is attributed to ceramic nature of hard coating as shown by microstructure by $\mathrm{T} 2$ treatment. However, cryogenic treatment is exhibited by dense tempered martensitic structure with little or no retained austenite as shown by T3, but loose tempered structure is shown by hardened and tempered structure with residual amount of retained austenite as indicated by $\mathrm{T} 1$ treatment (See Fig. 1). Finally control exhibit shows pearlite and ferrite as indicated by T4. It is needless to mention that the lowest wear resistance is noted by control sample which is attributed to soft phases that are present in microstructure.

\section{Effect of heat treatment, material, load and speed}

A statistical analysis was carried out to find out the significant differences between the treatments. Analysis of variance shows that the effect of heat treatment on wear loss was significant at 1 per cent level. The analysis further reveals that the interaction effect of heat treatment, load and speed was also found significant. This result is in confirmation with the findings of Chahar and Tiwari (2009) and Sapkale and Tiwari (2017) who also reported a linear relationship between wear and Material.

Minimum wear loss of $0.0064 \mathrm{~g}$ was observed in $\mathrm{T}_{2}$ followed by $0.0071 \mathrm{~T}_{3}, 0.0113 \mathrm{~T}_{1}$ and $0.0684 \mathrm{~g} \mathrm{~T}_{4}$ treatments (Fig. 3). The wear loss of materials with harden and tempered, coated and cryogenic treatments were found 35.49 , 66.42 and 53.52 per cent less than that of the untreated material

\section{Interaction effect of independent variables (two variables) on wear loss}

Based on the $\mathrm{CD}$ values given for 1 and 5 per cent levels of significance, overall interaction effect of L x SP, SP x T on wear loss was found to significant at 1 per cent level. At each load, the wear loss was found to be minimum in EN 45 material with chromium nitride treatment. Cumulative weight loss during abrasion was highest for control sample $\mathrm{T}_{4}$ and lowest for chromium nitride $\mathrm{T}_{2}$. The wear loss of sample with Chromium nitride, cryogenic and hardening and tempering treatments were found $66.40,53.46$ and 35.49 per cent less than that of the control sample.

\section{Effect of applied load on wear}

The wear loss of materials with selected heat treated samples as a function of applied load at various speeds is shown in Figures. It is evident from these figures that the wear loss increases with increase in applied load and also increases with increase in speed of operation irrespective of heat-treatment 
schedule. The increase in wear rate with applied load is quite obvious. However, these figures, in general, demonstrate that the trend in variation in the wear rate with applied load is almost invariant to the hardness of the material.

Table.1 Summary of test parameters used for the cryogenic treatment

\begin{tabular}{|l|l|l|}
\hline Sr. No. & Description of parameters & Details \\
\hline $\mathbf{1 .}$ & Room temperature & $27^{\circ} \mathrm{C}$ \\
\hline $\mathbf{2 .}$ & Intermediate temperature & $-30^{\circ} \mathrm{C}$ \\
\hline $\mathbf{3 .}$ & Soaking time for intermediate temperature 1 & $10 \mathrm{~min}$ \\
\hline $\mathbf{4 .}$ & Intermediate temperature 2 & -86.4 \\
\hline $\mathbf{5 .}$ & Soaking time for intermediate temperature 2 & $20 \mathrm{~min}$ \\
\hline $\mathbf{6 .}$ & Intermediate temperature 3 & $-120^{\circ} \mathrm{C}$ \\
\hline $\mathbf{7 .}$ & Soaking time for intermediate temperature 3 & $40 \mathrm{~min}$ \\
\hline $\mathbf{8 .}$ & Intermediate temperature 4 & $-155^{\circ} \mathrm{C}$ \\
\hline $\mathbf{9 .}$ & Soaking time for intermediate temperature 4 & $20 \mathrm{~min}$ \\
\hline $\mathbf{1 0}$ & Final temperature & $-185^{\circ} \mathrm{C}$ \\
\hline $\mathbf{1 1}$ & Final Soaking period & $16 \mathrm{~h}$ \\
\hline
\end{tabular}

Table.2 Summary of the test parameters used to evaluate the dry sliding wear test

\begin{tabular}{|c|l|l|}
\hline Sr. No. & Description of parameters & Values \\
\hline $\mathbf{1}$ & Load, $\mathrm{N}$ & $40,60,80,100$ \\
\hline $\mathbf{2}$ & Sliding speed, $\mathrm{m} / \mathrm{s}$ & $0.5,1,1.5,2$ \\
\hline $\mathbf{3}$ & Time, min & $50,25,16,12$ \\
\hline $\mathbf{4}$ & Sliding distance, $\mathrm{m}$ & 1500 \\
\hline $\mathbf{5}$ & Cross-sectional area, $\mathrm{mm}^{2}$ & 28.27 \\
\hline $\mathbf{6}$ & Pressure, MPa & $1.41,2.12,2.82,3.53$ \\
\hline $\mathbf{7}$ & Specimen dimension, $\mathrm{mm}$ & $\Phi 6 \mathrm{X} 15 \mathrm{~mm}$ \\
\hline
\end{tabular}

Fig.1 Schematic T-T diagram illustrates processing steps for EN45 steel

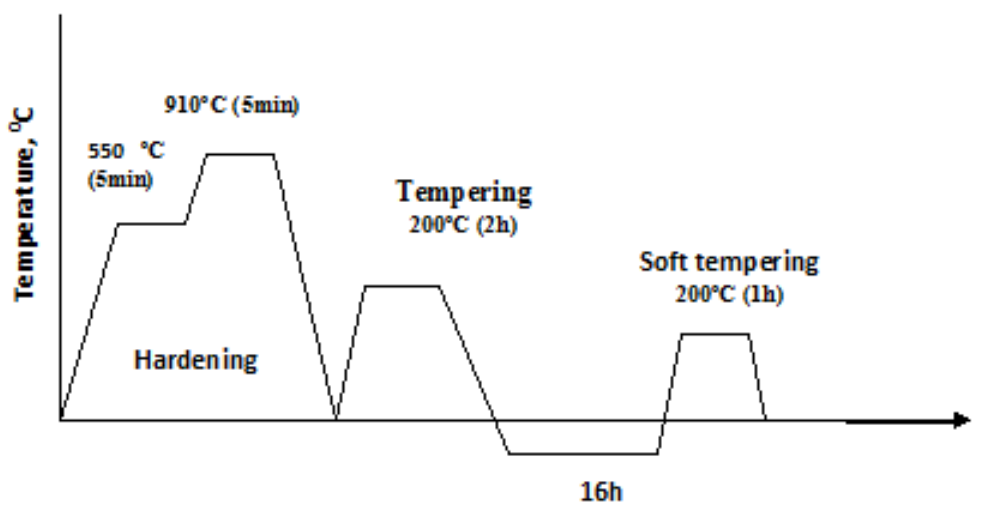


Fig.2 Microstructure analysis of material EN 45

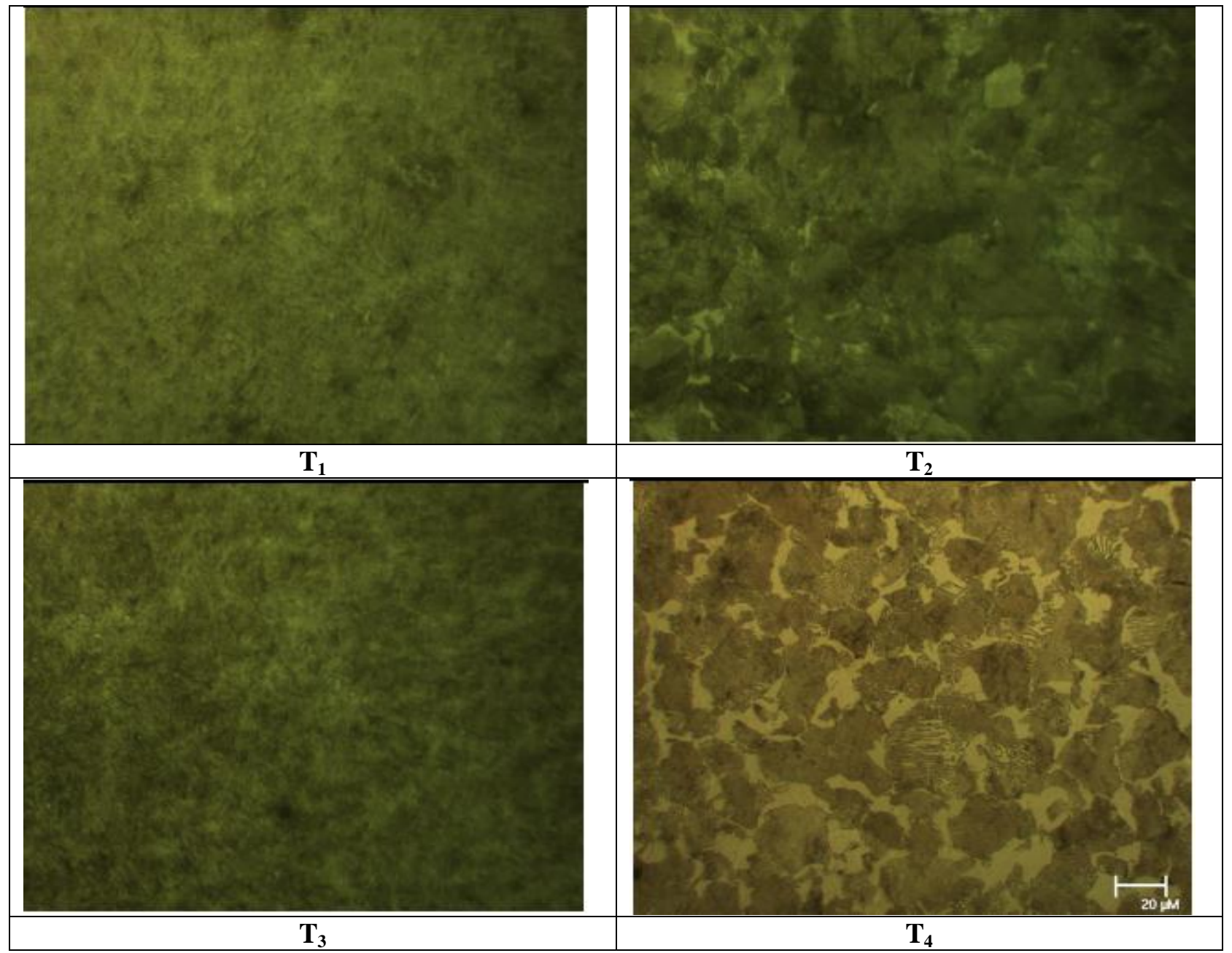

$T_{1}$ : Microstructure shows tempered martensite

$\mathrm{T}_{2}$ : Microstructure shows Chromium nitride coating

$T_{3}$ : Microstructure shows dense tempered martensite

$\mathrm{T}_{4}$ : Microstructure shows pearlite and ferrite matrix

Fig.3 Wear loss of different heat treatments

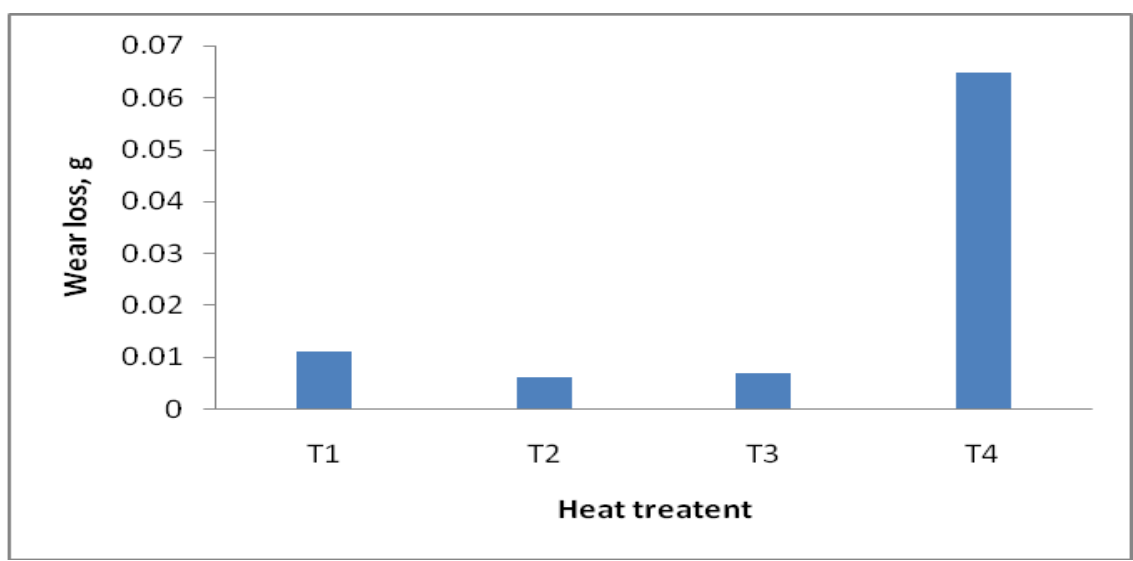


Fig.4 Sample of EN 45 before and after wear loss

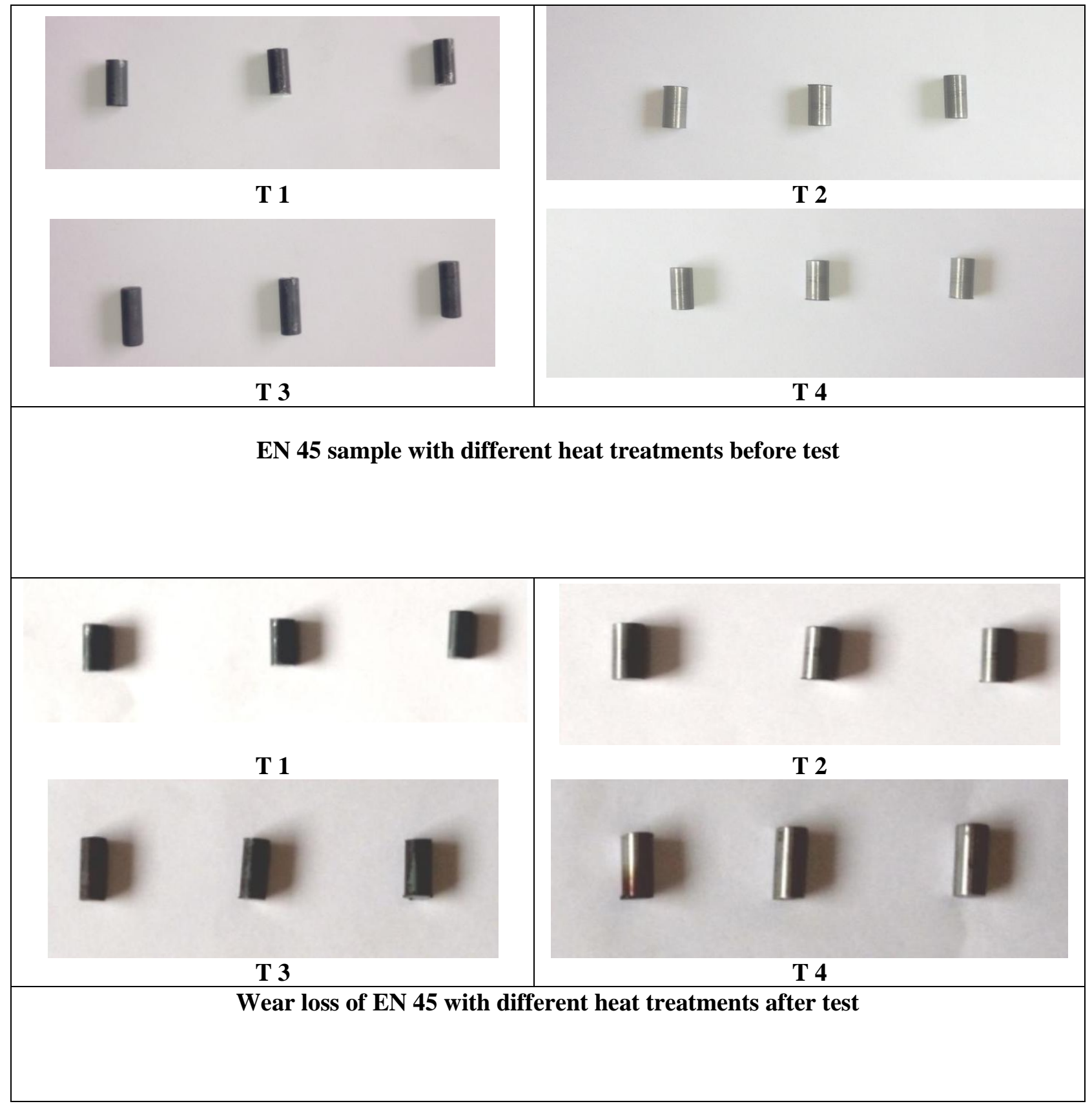




\section{Int.J.Curr.Microbiol.App.Sci (2019) 8(3): 745-754}

Fig.5 Wear loss of En 45with heat treatments at different speed

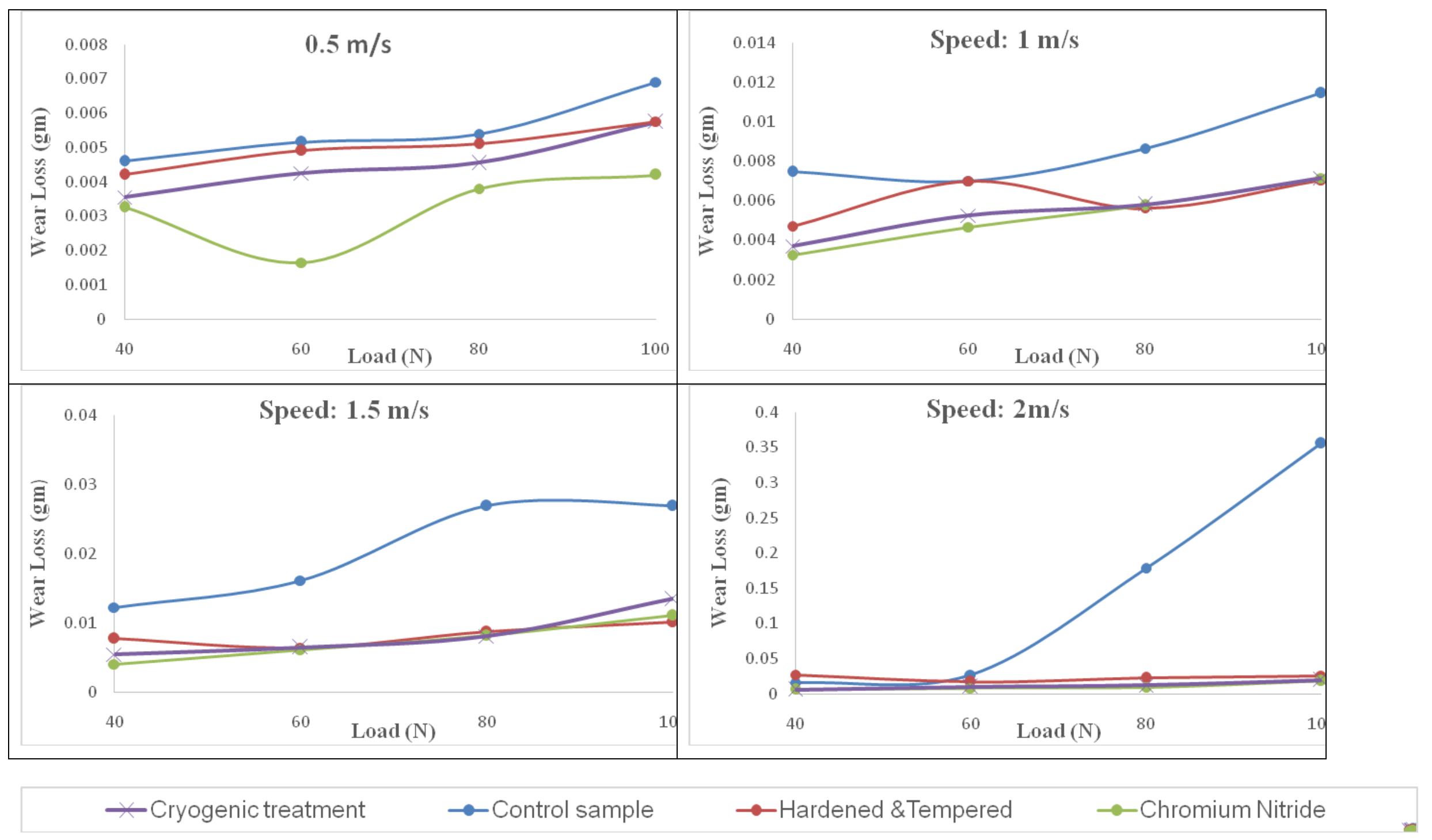




\section{Int.J.Curr.Microbiol.App.Sci (2019) 8(3): 745-754}

Fig.6 Wear loss of type of crop cutting blade materials by the heat treatments at different speed at loads $40 \mathrm{~N}$

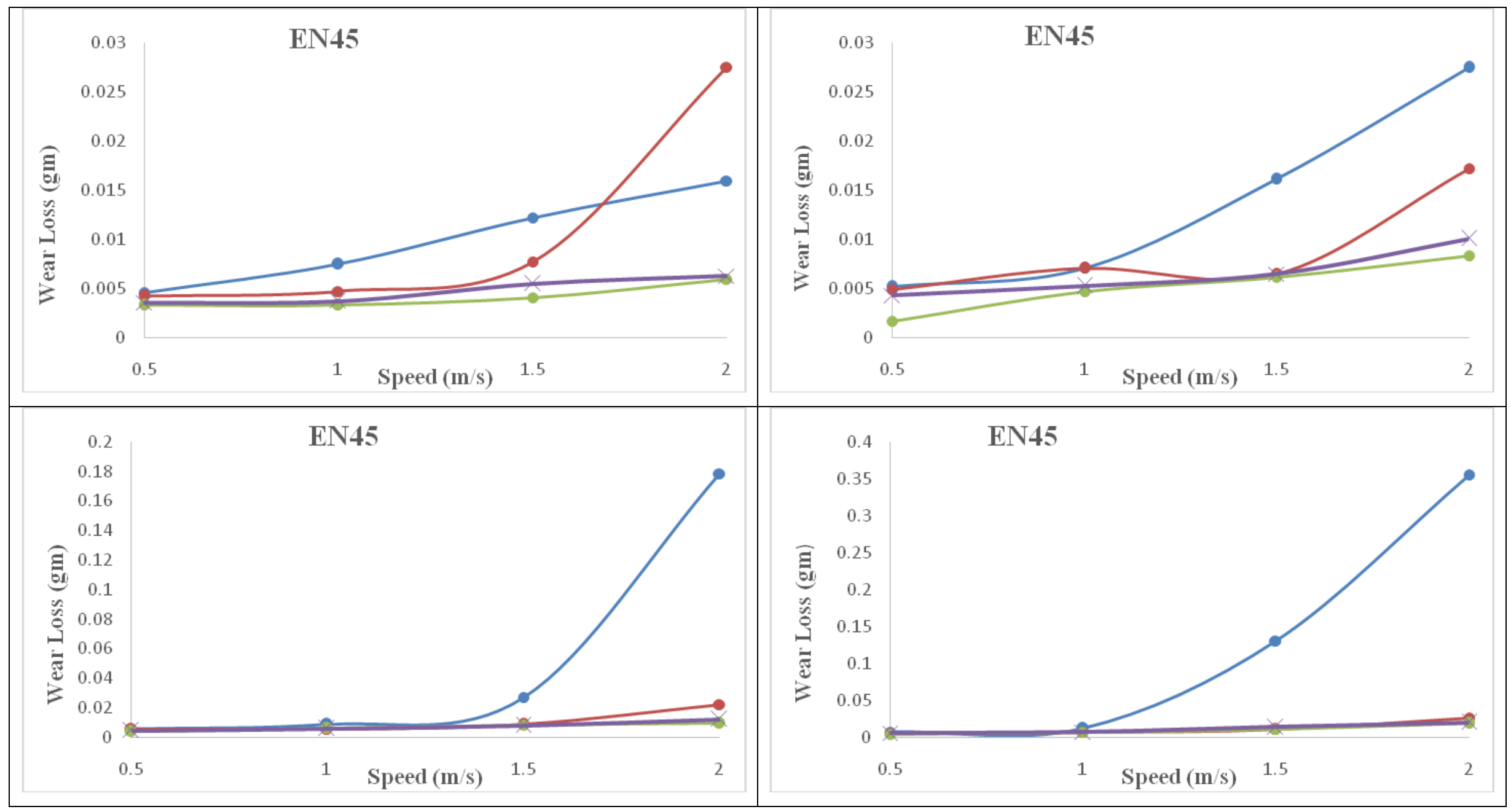

$\leftarrow$ Cryogenic treatment

$\rightarrow$ Control sample

$\multimap$ Hardened \&Tempered

$\rightarrow$ Chromium Nitride 
The wear loss of materials with selected heat treatments at speed $0.5 \mathrm{~m} / \mathrm{s}$ is shown in Figure 6. It is evident from figure that the wear loss increases with increase in applied load irrespective of heat-treatment. The wear loss of materials with selected heat treatments at speed $0.1 \mathrm{~m} / \mathrm{s}$ is in hardening and tempering wear loss wear loss increases with increase in applied load up to $60 \mathrm{~N}$, whereas after 60 and $80 \mathrm{~N}$ wear loss decreased with increased load. The wear loss of samples with selected heat treatments at speed $1.5 \mathrm{~m} / \mathrm{s}$, the wear loss increases with increase in load. Minimum wear was found in chromium nitride treatment for all speed. All heat treatment behave same manner but control sample wear loss was rapidly increase after $60 \mathrm{~N}$.

To study the effect of load on wear loss, a functional relationship was determined in the following form at different speed. The equation of wear was found

\section{Effect of speed on wear}

Wear loss was increased with increased speed. Similarly, load 60, 80 and $100 \mathrm{~N}$ is shown in Fig. 7. Wear loss was decreased with increased speed in all material. Minimum wear loss was observed in chromium nitride treatment.

On the basis of results and discussion following conclusions are made:

Highest wear resistance of coating is due to inherent wear resistance of chromium nitride, which has highest hardness of $3100 \mathrm{VHN}$ (to confirm exact hardness reported by SMT). The wear loss of materials with selected heat treated samples as a function of applied load at various speeds and loads, the wear loss increases with increase in applied load and also increases with increase in speed of operation irrespective of heat-treatment schedule. Analysis of variance shows that the effect of heat treatment on wear loss was significant at 1 per cent level.

\section{Acknowledgement}

Most estimably I accord my humble reverence and thanks to Dr. N. B. Dhokey, Professor \& Head, Department of Metallurgy \& Material Science, Govt. College of Engineering, Pune for the guidance and help to me round the clock by providing me the precious facilities.

\section{References}

Cho, Revilla-Gomeza, J-Y, Buffierea, C. Verdua, C. Peyracb, L. Daflonb, F. Lefebvre. 2013. Assessment of the surface hardening effects from hammer peening on high strength steel. 2013. Science Direct-Procedia Engineering. 66 (2013).150-160.

Gupta, A.K., Jesudas, D.M., Das, P.K. and Basu, K. 2004. Performance evaluation of different types of steel for duck foot sweep application. Biosystems Engineering, 88 (1), 63-74.

Sing, J., Sing L. P., and Kaushik A. 2013. Enhancing wear resistance of En45 Spring steel using cryogenic treatment. Friction and Wear Research, 1(2), 22-27.

Spakale, P. R. and Tiwari, G. S. 2017 Wear characteristics of reversible cultivator shovel. Contemporary Research in India, 7(4): 86-95

\section{How to cite this article:}

Bastewad, T.B., S.H. Thakare, P.R. Sapkale, A.K. Kamble and Karale, D.S. 2019. Effect of Heat Treatments on Wear Behavior of En 45 Spring Steels. Int.J.Curr.Microbiol.App.Sci. 8(03): 745-754. doi: https://doi.org/10.20546/ijcmas.2019.803.091 